\title{
Editorial Policy/Instructions for authors
}

\section{Objective of the journal}

This journal aims to publish papers of researches on diseases of sick children, achieved though academic collaboration. We aim to release pioneer researches and technologies by crossfield collaboration, and to create unprecedented community of academic collaboration.

Papers published in traditional science journals are described according to "the infallible scientific fact" Such journals may make research papers which are scientifically correct but poor in originality or novelty. This journal, ACSC, publishes research papers created by flexible ideas which are not bound by existing findings and knowledge, and through collaboration among researchers from different fields - academic collaboration-. Novel and original researches thruogh academic collaboration are to be made public even if they are not sufficiently verified from a scientific standpoint. We expect this journal would provide a help for innovative creations.

\section{Content of researches}

We mainly publish researches on diseases of sick children but cover all the research fields containing biology and medicine to science, agriculture, engineering, pedagogy, sociology or ethics because this journal aims to focus on academic collaborations. Articles shall clearly describe about what studies or technologies are collaborated, what is novel, what is the objective, what is the vision for the future.

Author's background, affiliation (university, public institution, company) or collaborator does not matter as long as it is an unprecedented research or technology development through technological collaboration from different fields.

\section{Qualifi cation of contributors}

1 ) There are no limitations regarding author affiliation or discipline as long as the content of the submitted article meets the editorial policy of Academic Collaborations for Sick Children. And it should require all authors' signatures to prove all of them agree by common consent to the content of submitted article.

2 ) The submitted article should have never been published in any journals and it should not infringe anycopyright.

3 ) The submitted article should comply with ethics code of the author's institution and Helsinki Declaration. And the author should take every care and responsibility to protect patient's privacy for case presentations which concern personal identification.

\section{Manuscript}

2 . 1 General

1 ) Article may be submitted in Japanese or English. Accepted article will be translated in English or Japanese under the responsibility of University of Tokyo Academic collaborations Society. Both the original and translate articles will be published at a time.

2 ) The manuscript shall be prepared using word processors or similar devices and printed on A4 size portrait sheet of paper. Article in Japanese should be written horizontally in hiragana, Chinese- characters in common use and contemporary Japanese syllabic writing. Article in English should be written double space, printed onto A4 paper keeping space of $5 \mathrm{~cm}$ on the left, right, top and bottom. Alphabets, numbers and symbols should be one-byte characters. And dates should be indicated in western calendar.

3 ) File type for the manuscript shall be MS Word format (preferred) or Text format.

\section{2 . 2 Structure}

1 ) The manuscript should include a title (including subtitle), the name(s) of author(s), collaboration, abstract, main text, keywords (about 5 words), affiliation, contact, runnning title.

2 ) The length of manuscript shall be about 4 printed pages including fi gures, tables and photographs.

3 ) The title should be about 10-20 Japanese characters (5-10 English words).

4 ) The collaboration should describe each fields of collaboration as 
5 ) The abstract should include abstract of research content and purpose of cross-field collaboration. It should be around 400 characters in Japanese (150 words or less in English).

6 ) The main text should be organized in the sequence; introduction, methods, results, discussion, conclusion and issues, references, website references. It shall be about 5000-6000 characters in Japanese or same volume in English printed out (2500-3000 words).

\section{2 . 3 Figures (illustrations, graphs, photographs)} and tables

1 ) Figures and tables should be enumerated. They should have a title and an explanation, and position in the text should be clearly indicated. If size of figures and tables are specified, you shall contact to the inquiries.

2 ) For illustrations and graphs, clear originals (color accepted) that can be used for printing or image files (resolution $350 \mathrm{dpi}$ or higher in the final print size) should be submitted. Color fi gures in PDF files will be displayed in RGB and for the print edition RGB is digitally converted to CMYK. Therefore, the color proof is sent to author after acceptance of their paper.

3 ) For photographs, clear prints (color accepted) or image files (resolution $350 \mathrm{dpi}$ or higher in the final print size) should be submitted.

4 ) Tables files should be MS Excel format (preferred).

5 ) Image fi les should specify fi le types; Tiff. PDF file is not acceptable.

\section{4 References}

When cited in the text, reference number should be superscript. References should be listed in order of citation in the main text. All authors should be included in reference list unless there are more than four, in which case only the first three authors should be given following by 'etc.' or 'et al.' Journal - [No.] Author(s): Title of article. Title of journal,

Volume (Issue), Starting page-Ending page

(Ex.) 1. Donnez J, Dolmans MM, Demylle D, et al : Livebierth after orthotropic transplantation of cryopreserved ovarian tissue. Lancet, 2004 ; 364(9443) : 1405-10.

Book (single/multi-author(s)) - [No.] Author(s): Title of book, Starting page-Ending page, Publisher, Place of publication

(Ex.) (2) Yoshikazu Ikuta : Micro-surgery (First edition), 1997, pp280-85, Nankoudou, Tokyo

(3) Susumu Tamai : Micro-surgery standard orthopedic surgery (the 5th edition) (supervised by Kazushi Hirohata, edited by Kazuo Terayama \& Haruo Tsuji), 1998, pp177-185, Igakushoin, Tokyo

\section{Submission}

One printed copy and electronic fi le (CD-ROM or DVD) of manuscript should be submitted to following address;

Makoto Mihara, M. D.

Department of Plastic and reconstructive surgery, University of Tokyo 7-3-1 Hongo, Bunkyo-ku, Tokyo, 113-8655, Japan

The submitted article will not be returned.

\section{Proofreading}

Proofreading by author(s) of articles after type setting is complete will be done once. In principal, only corrections of printing errors is allowed in the proofreading stage.

\section{Copyright}

The copyright of articles published in Academic Collaboration for Sick Children shall belong to Japan Academic Collaboration Medical Society.

\section{Revision of the instruction for authors}

The instruction for authors described above may be revised as needed under the responsibility of the editorial committee.

\section{Posting fee}

1 ) The article shall be published at no cost up to 4 pages. In case they exceeded the allocated pages, the author shall be charged JPY20,000 per page. However articles (review, special feature) invited by the editorial committee will be published free of cost.

2 ) Extra cost for special printing shall be charged the author.

3 ) For express publishing of an article, all the cost shall be charged the author. 